Commentary on The Impact of Implementing an "Incredible Years" Group Within a Family Living Unit in a Transitional Living Shelter: The Case of "Cathy"

\title{
Considerations for the Dissemination of Incredible Years in Welfare Systems: Implications of the Case of "Cathy" for Intervention in the Foster Care System
}

\author{
ARIELLE S. GARTENBERG ${ }^{\mathrm{a}, \mathrm{b}, \mathrm{c}} \boldsymbol{\&}$ L. ROBIN LANG, ${ }^{\mathrm{a}, \mathrm{b}}$ \\ ${ }^{\text {a }}$ Graduate School of Applied \& Professional Psychology (GSAPP), Rutgers University \\ ${ }^{\mathrm{b}}$ Foster Care Counseling Project, Center for Applied Psychology, GSAPP, Rutgers University \\ ${ }^{\mathrm{C}}$ Correspondence regarding this article should be addressed to Arielle Gartenberg, Center of Applied Psychology, \\ c/o Rutgers University GSAPP, Suite A, 41 Gordon Road, Piscataway, NJ 08854, USA. \\ Email: arielle.gartenberg@rutgers.edu
}

\begin{abstract}
The Incredible Years (IY) Parent and Child Series are evidence-based interventions that increase knowledge and mastery of parenting, mood regulation, and interpersonal problem solving strategies for caregivers while developing similar social and emotional skills in their children. Rogers, Bobich, and Heppell (2016) use a case study approach to examine the effectiveness of adaptations of the IY program for delivery in a transitional housing shelter. They describe strategies for modifying IY to meet the needs of a vulnerable population within the context of the shelter and the broader welfare system. In this commentary, the difficulties commonly experienced by youth like "Cathy" as a function of homelessness and trauma are discussed. Aspects of IY and its adaptation are examined as they highlight (1) essential elements of psychological interventions with clients exposed to trauma, and (2) barriers and facilitators in the delivery of evidence-based treatments within complex natural settings and systems of care. These considerations are salient for practitioners treating youth and families involved in the child welfare system and foster care. The most vital adaptations presented in the Case of Cathy and the IY literature are reviewed to address anticipated pragmatic barriers and therapeutic issues in the implementation of IY for youth in these systems.
\end{abstract}

Key words: Incredible Years (IY); child welfare; foster care; trauma-informed care; trauma; homelessness; attachment; parenting; externalizing behaviors; case study; clinical case study

Rogers, Bobich, and Heppell (2016) offer a rich clinical case that raises issues in the delivery of evidence-based interventions to youth and families with histories of transience and trauma. In the Case of Cathy, the authors build upon the standard Incredible Years (IY) program 
Considerations for the Dissemination of Incredible Years in Welfare Systems:

and integrate recommendations for treatment within the child welfare system to effect inspiring change in 4-year-old Cathy, her mother, Ms. Z, and their relationship. Similar to Cathy and Ms. Z, many families involved with child welfare systems have been exposed to trauma, poverty, and instability_risk factors that strain parent-child attachments and hinder the acquisition of adaptive behavioral, social, emotional, and academic skills. In this commentary, we discuss the common experiences of adversity among this family and others in transitional housing or the child welfare system. In light of their trauma histories (i.e., Ms. Z's history of relationship violence, Cathy's potential exposure to domestic violence, unstable housing in early years), we summarize best practices for trauma-informed care and trauma-informed systems, review the important adaptations in Cathy's case, and discuss broadly the benefits of these adjustments for families with similar histories and presenting problems.

\section{HOMELESSNESS AND FOSTER CARE}

\section{Trends}

There is a high crossover between homelessness and foster care (Zlotnick, 2009). Studies of homeless families suggest that $24 \%$ are involved in the foster care system, and homeless youth are 34 times more likely to enter the foster care system than same-age peers in the United States (Children's Bureau, 2005). In a longitudinal cohort study of families involved in child welfare services in a U.S. city, $64 \%$ of youth whose mothers experienced homelessness at least once were involved in the foster care system, compared to 39\% of other low-income mothers and 39\% of all other mothers included in the child welfare sample (Culhane, Webb, Grim, \& Metraux, 2003). This is consistent with an earlier study of a foster care system in California, in which nearly $49 \%$ of randomly selected foster care children had been removed from homeless parents (Zlotnick, Kronstadt, \& Klee, 1998).

The experiences of homeless and foster care youth can be similar in many ways. Although a causal relationship between homelessness and foster care involvement has not been established, there is a consistent bidirectional relationship between these conditions. They often result from exposure to similar adversities and elevate risk for common psychosocial difficulties. For instance, Aratani (2009) and Zlotnick (2009) summarize literature on the themes of trauma, poverty, mental health, and substance abuse in cycles of homelessness in families, factors which represent risk and reasons for involvement in the foster care system. Although Cathy had not been involved in foster care, Rogers and colleagues (2016) emphasize the risk associated with homelessness, including exposure to parental psychopathology, inadequate support systems, family problems, parental loss, violence, school and placement disruptions, and exposure to violence (Menke, 1998; Obradović, 2010). Children who are homeless or involved in the foster care system are more likely than their same-age peers to experience difficulties and delays in multiple areas of functioning, including in the behavioral, social, emotional, and academic arenas (Anooshian, 2005; National Center on Family Homelessness, 1999, 2009, 2011; Lee et al., 2010; National Coalition for the Homeless; 2009; Neiheiser, 2015; Pecora, Jensen, Romanelli, Jackson, \& Ortiz, 2009; Pilowsky 1995; Ehrle \& Geen 2002; Ehrle, Geen, \& Clark 2001). 
Youth in the child welfare system exhibit significantly greater psychological difficulty compared to youth with similar backgrounds (Kortenkamp \& Ehrle, 2002; Pilowsky, 1995) and youth in the general population (Pecora, Jensen, Romanelli, Jackson, \& Ortiz, 2009). Compared to youth living with high risk parents, children in the child welfare system are more likely to have emotional and behavioral problems and less likely to be engaged in school and social activities (Kortenkamp \& Ehrle, 2002; Pilowsky, 1995). There are consistently disproportionate rates of psychopathology among youth currently and formerly in foster care. In a national survey on the mental health needs of youth involved in child welfare, nearly $48 \%$ of children and adolescents in foster care exhibited clinically significant emotional or behavioral problems (Burns et al., 2004). Youth in foster care are more likely to have at least one lifetime diagnosis compared to the general population. Accordingly, rates of PTSD and various internalizing and externalizing conditions are higher among foster care children than their same-age peers (Grayson, 2012; Pecora et al., 2009). These trends underscore the need for youth in these systems to have access to high quality mental health services.

Studies on the mental health of youth in foster care reflect not only the high demand for quality services, but also significant barriers to accessing them. Recent statistics show that most states fail to meet the psychological needs of victims of abuse and neglect in foster care (Huber \& Grimm, 2004). The National Study of Child \& Adolescent Well-Being revealed that youth in the child welfare system utilize more psychological services than youth in the general population. Still, $75 \%$ of children who were involved in the system due to abuse or neglect and demonstrated clinically significant impairment had not received treatment within a year of the abuse or neglect investigations (Stahmer et al., 2005). Mental health services are not readily available, and the services provided are not necessarily evidence-based (Cosgrove, Frost, Chown, \& Anam, 2013; Webster-Stratton \& Reid, 2010).

\section{Barriers to Treatment}

There are unique barriers to providing care to foster care youth and youth at risk of removal. Some challenges relate to the training, knowledge, and capacities of practitioners, caseworkers, and resource parents. For instance, service providers and families may have limited knowledge of evidence-based treatments. Despite awareness of best practices, implementation and consultative support and training might be hindered by the overall lack of resources in welfare systems (Grayson, 2012). Further, difficulty engaging parents and caregivers presents an impactful barrier to treatment. Parents of children with conduct problems might be unable to participate in treatment due to life stress, their own psychopathology, or lack of motivation to trust and engage in systems of care. These factors might also preclude caregivers from utilizing strategies discussed in therapy or recommended by practitioners (Webster-Stratton \& Reid, 2003). Providers and parents might also confront challenges in engaging children. Youth who have experienced abuse, neglect, abandonment or other losses often develop insecure styles of attachment and may be slow to trust adults and their actions, such as praise (Webster-Stratton \& Reid, 2003). 
Considerations for the Dissemination of Incredible Years in Welfare Systems:

Implications of the Case of "Cathy" for Intervention in the Foster Care System

A. S. Gartenberg \& L. R. Lang

Pragmatic Case Studies in Psychotherapy, http://pcsp.libraries.rutgers.edu

Volume 12, Module 2, Article 3, pp. 124-138, 06-29-16 [copyright by authors]

Related barriers to accessing quality care includes inadequate screenings and needs assessments; the complexity of children's needs; limited coordination amongst providers and between resource and birth parents; insufficient financial resources and a paucity of care options; and instability in placements (Austin, 2005; Grayson, 2012; Horwitz, Owens \& Simms, 2000; Landsverk, Burns, Stambaugh, \& Rolls Reutz, 2006; Marshall, 2004; McMillen et al., 2004; Rosenkranz, 2006; Rubin et al., 2004; Zima, Bussing, Crecelius, Kaufman, \& Belin, 1999). Thus, awareness, access, and engagement are difficult for many involved in children's treatment.

Some aspects of the broader systems of care and related policies interfere with the delivery of quality services. For instance, many organizations target specific populations and are restricted by the client's current living status or expectations of grant funders. Children in homeless shelters or the foster care system might experience premature disruptions in their services or transitions in agencies and providers. For example, this can occur with the turnover of agency personnel. Turnover sometimes occurs quickly and with limited or no opportunity to process and prepare for the end of the therapeutic (or other) relationship. When homeless children enter foster care, or children in foster care exit the system (e.g., following reunification), they might be entitled to different types of services. Even when eligible for the same services, the agencies and providers responsible for care might change (Zlotnick, 2009). These situations can occur when services target specific populations or problem areas. For instance, some resources target youth and families in foster care, while others might target reunified families or families in transitional housing. Children in foster care might receive treatment with certain providers through a designated agency, but have to terminate and transition to new providers elsewhere once reunified. Such transfers are counter-indicated during periods of adjustment (e.g., reunification) when consistency in routine and connection to other attachment figures is particularly important.

Similarly, geographical and financial constraints hinder consistent access to quality care. Transient populations more vulnerable to disrupted services might experience delays and difficulties in initiating services at a new location (Zlotnick, 2009). Once treatment has ended due to changes in placement status, families might have to wait to initiate care through other agencies (e.g., due to waitlists, delays in referral and intake processes). Such disruptions represent barriers to treatment that are potentially more harmful for insecurely attached and traumatized children and parents, who might require more time and specialized care in order to feel safe in therapeutic settings.

The coordination of care providers is a key issue in the delivery of consistent and comprehensive care for families who have experienced homelessness, foster care involvement, or both. Families involved in child welfare services often have complex and varied needs. As such, they might be involved with multiple agencies and providers. Although families can benefit from exposure to professionals with various areas of expertise, their progress in treatment and access to services may be stymied by disagreements or insufficient communication and collaboration among providers. "Consequently, service dissemination can become confusing, duplicative, disjointed, fragmented, or forgotten” (Zlotnick, 2009, p. 322). Consistency and coordination of trauma-informed and family-focused care are particularly important for transient 
Considerations for the Dissemination of Incredible Years in Welfare Systems:

Implications of the Case of "Cathy" for Intervention in the Foster Care System

A. S. Gartenberg \& L. R. Lang

Pragmatic Case Studies in Psychotherapy, http://pcsp.libraries.rutgers.edu

Volume 12, Module 2, Article 3, pp. 124-138, 06-29-16 [copyright by authors]

populations for whom instability and abruptly severed relationships can exacerbate the impact of previous traumas and attachment injuries.

\section{Trauma-Informed Recommendations}

In light of the prevalence of mental health conditions and paucity of effective and accessible services for foster care youth, strategies for overcoming barriers and facilitating meaningful treatment must be considered. Broadly, systemic changes might be considered to ensure that treatment of youth in foster care or other welfare systems have access to comprehensive, long-term, and trauma-informed therapy (Zlotnick, 2009). This includes policylevel changes in the prevention and early intervention for at risk youth, enhanced assessments and screenings to identify youth in need and the appropriate level of care, and development of appropriate intervention options, which include educational and therapeutic programs for providers and caregivers.

At the policy-level, Zlotnick (2009) advocates for a careful evaluation of the labels and classifications as they focus intervention initiatives and determine eligibility for treatments. The high crossover between homelessness and foster care involvement reflects a tendency for multiple service providers to be connected to disadvantaged families in order to meet their various needs. The current system of service delivery often requires transitions between these providers and risks premature termination of some services and abrupt separation from familiar supports and attachment figures. The organization of systems of care and guidelines for funding might be reformed to promote more comprehensive, consistent, and continuous care to minimize disruptions in treatment and maximize long-term gains for families and children.

Policies governing the child welfare system impact risk, treatment, and outcome in important ways. Most notably, efforts to promote permanency of placements promise to minimize risk for youth in foster care and enable stability and continuity of care necessary to facilitate wellness. Placement changes elevate risk for a number of deleterious outcomes. The Northwest Foster Care Alumni Study (Pecora et al., 2005) found that placement stability was associated with a $22 \%$ reduction in negative mental health outcomes. Stability helps children to feel comfortable. Routines and familiarity can reduce anxiety and uncertainty by helping children to anticipate future events and feel safe. Stability is important for youth and can be promoted through trauma-informed care.

Recommendations for increasing access to and benefits from psychological services include the training of all providers and caregivers in trauma-informed practices and positive parenting skills. Trauma-informed care ensures sensitive identification and treatment of traumarelated needs while avoiding re-traumatization. It permits flexible adaptations that meet the complex needs of vulnerable and diverse populations including families involved in foster care or facing homelessness (Chadwick Trauma-Informed Systems Project; National Child Traumatic Stress Network, 2008). A trauma-informed child welfare system is “...one in which all parties involved recognize and respond to the varying impact of traumatic stress on children, caregivers, and those who have contact with the system. Programs and organizations within the system 
Considerations for the Dissemination of Incredible Years in Welfare Systems:

Implications of the Case of "Cathy" for Intervention in the Foster Care System

A. S. Gartenberg \& L. R. Lang

Pragmatic Case Studies in Psychotherapy, http://pcsp.libraries.rutgers.edu

Volume 12, Module 2, Article 3, pp. 124-138, 06-29-16 [copyright by authors]

infuse this knowledge, awareness, and skills into their organizational cultures, policies, and practices. They act in collaboration, using the best available science, to facilitate and support resiliency and recovery” (Klain \& White, 2013, p. 5).

Trauma-informed recommendations for child welfare agencies include ongoing collaboration throughout and beyond activities, such as education, evaluation, and treatment. All stakeholders in a child's care (i.e., courts, attorneys, advocates, child welfare agencies, all service providers, parents, caregivers, and youth as developmentally appropriate) should participate in trainings focused on the impact of trauma, its manifestation, and proper treatments. All parties are expected to be aware of and/or involved in the evaluations of trauma-related needs and referrals for evidence-based, trauma-specific treatments. Intervention should begin as early as possible and continue as needed (Zlotnick, 2009) to address the underlying context and causes of trauma as well as manifested symptoms (Klain \& White, 2013). Treatments are also expected to involve parents, caregivers, and related providers (e.g., child welfare workers) in order to provide necessary consultation, psychoeducation, and support. In order to help children most effectively, all child-serving systems must employ an "integrated community approach to ensure seamless delivery of services” (Klain \& White, 2013, p. 11).

There is an increasing emphasis on family involvement in children's treatment. Including parents in interventions allows for the repair and restructuring of family relationships as well as skill building across family members. Caregiver involvement is essential for promoting maintenance and generalization of gains (Grayson, 2005; Virginia Commission on Youth, 2005). A comprehensive treatment program will develop caregivers' capacities to use positive parenting and adaptive life skills, and monitor the need to coordinate mental health and substance abuse services (Zlotnick, 2009). For transient families, the impact of the parents' health and the importance in their children's lives must be recognized (Zlotnick, 2009). Practitioners may view family involvement as an opportunity to empower disadvantaged individuals through collaborative assessment, treatment planning, intervention, and service evaluation (Grayson, 2012). Regardless of families' housing arrangements or child welfare involvement, birth parents should be included in these activities to the greatest extent possible (Grayson, 2012).

Trauma-informed practices can enhance service delivery at multiple levels through systemic or program-wide policies and strategies in the therapy room. A survey of program developers yielded a list of ten essential issues to address in evidence-based treatments for youth in foster care. These include: (1) promoting secure attachments, (2) affect regulation, (3) socialinterpersonal skills training, (4) parenting skills of caregivers, (5) working with multiple caregivers, (6) integrating/coordinating with social service agencies and child's social environment, (7) conducting trauma work around physical, sexual, and emotional abuse and neglect, (8) engaging in family work to improve relationships, (9) preparing for reunification, and (10) reducing family conflict (Baker, Brown, Schneiderman, Sharma-Patel, \& Berrill, 2013).

Incredible Years was one of 5 programs that met all 10 criteria, and the only one of these 5 programs to have published positive findings on implementation with foster care youth (Baker et al., 2013). Extant literature on the delivery of IY in foster care systems yields promising 
results. Studies in the United States and United Kingdom reveal benefits for children, birth parents, and foster caregivers. Programs including birth and/or foster parents decrease children's conduct symptoms and overall externalizing behavior (Bywater et al., 2010; Hutchings \& Bywater, 2013; Linares, Montalto, Li, \& Oza, 2006; Marcynyszyn, Maher, \& Corwin, 2011; McDaniel, Braiden, Onyekwelu, Murphy, \& Regan, 2011; Nilson, 2007). Preliminary research also revealed improved parenting skills and parental well-being as seen in increased empathy and social support, and decreased defensive responding, dysfunctional parent-child interactions, parental distress (Marcynyszyn et al., 2011), and foster parent depression (Bywater et al., 2010; Hutchings \& Bywater, 2013). An early study evaluated IY and an additional co-parenting component that yielded valuable improvements in parenting and collaborative co-parenting (Linares et al., 2006). When measured, foster caregivers also reported satisfaction with the program and the benefits it conferred (Nilson, 2007). In general, the IY program confers important benefits when delivered as part of trainings for birth and foster parents. Findings suggest that IY can be used as an acceptable early intervention to help caregivers manage challenging behavior and potentially promote placement stability (Bywater et al., 2010).

\section{INCREDIBLE YEARS PROGRAM AND ADAPTATIONS FOR HOMELESS AND FOSTER CARE YOUTH}

Below is a review of the components and adaptations of the IY program, including those used in the Case of Cathy, that are most promising for overcoming the aforementioned barriers to mental health care in homeless shelters and the foster care system.

\section{Advantages of the Core IY Program for Homeless and System-Involved Families}

The IY program is designed to maximize engagement, learning, and behavioral change in both parents and their children with various behavioral, social, and emotional difficulties. It is comprehensive in its foci on multiple areas of functioning and promotes generalization of gains across home, school, and social contexts (Webster-Stratton \& Reid, 2003). The program is an efficacious early intervention for youth demonstrating conduct problems and other externalizing behaviors and can be adjusted to meet the developmental needs of children ages 0-12.

IY employs social learning and cognitive-behavioral frameworks to systematically foster development of the self-regulation and interpersonal skills necessary to manage behavior and emotion, and to engage with others adaptively in order to seek help, solve problems, and build relationships. The core content of the parent program addresses these problem areas by strengthening family relationships and support networks, and building parent capacities to establish routines and utilize effective and non-punitive behavior management strategies (Webster-Stratton \& Reid, 2010). The multimodal format of sessions (e.g., discussion, live modeling, video modeling, goal-setting, practice, and child behavior charts) and simultaneous involvement of parents and children enhances a sense of competence and mastery. All these components promote observable change within relationships and in each person's own skill sets. 
Considerations for the Dissemination of Incredible Years in Welfare Systems:

Particular features of the IY program facilitate parent engagement and skill generalization. Most notably, collaboration is central to IY. The group leaders can actively seek members' perspectives and strive to balance collaboration with teaching. Members are encouraged to establish their own goals, identify strategies that appeal to and work for them, and self-monitor throughout each week. Leaders provide guidance and information about child development, parenting skills, and emotion regulation, but after seeking input and ideas from parents (Webster-Stratton \& Reid, 2012). This is crucial for parents who are mandated to participate in the program (Webster-Stratton \& Reid, 2012), like Cathy's mother and other group members who completed IY to fulfill the shelter's parenting class requirement. This is similarly vital for parents involved in the child welfare system who might be resistant to participating in required programs or working with leaders who appear to be part of the system.

Other aspects of the intervention facilitate engagement and skill generalization. Leaders consistently communicate their support and positive expectations for change and encourage members to support each other. Leaders consult with parents weekly, and ask parents to make buddy calls, wherein pairs of parents contact each other to review progress toward goals and provide encouragement. Supportive relationships between leaders and members can be particularly important for parents like Ms. Z, or parents involved in the foster care system (Webster-Stratton \& Reid, 2012). Parents with family histories of problematic interpersonal or emotional patterns can experience doubt in their abilities to break from detrimental cycles and create change within their families (Webster-Stratton \& Reid, 2012). Encouragement and consistent positive regard can be expected to increase self-efficacy and empowerment as well as engagement in treatment.

These core features of the IY program address many of the areas outlined by Baker and colleagues (2013). For instance, they teach children and parents skills for emotion regulation, relationship improvement, and conflict resolution. Caregivers learn parenting skills to promote their children's skill acquisition and usage and improve the parent-child dynamic. The IY program also meets broader recommendations for trauma-informed care, including opportunities for early intervention, family involvement, and collaborative and flexible approaches that are culturally sensitive and personally relevant. Additional adaptations to the IY program can target the remaining trauma-informed recommendations. These are discussed below in a review of the Case of Cathy and literature on IY in the child welfare system.

\section{IY Adaptations in the Case of Cathy}

Rogers, Bobich, and Heppell (2016) described trauma-informed adaptations to the IY program as well as modifications recommended for treatments within the child welfare system (Webster-Stratton \& Reid, 2012). Building on the standard program, the group leaders sought to implement treatment flexibly but within fidelity to ultimately foster significant growth in Cathy and Ms. Z. The leaders' approach to implementation in the transitional housing shelter enabled them to overcome barriers to access and address key areas in treatment. 
Considerations for the Dissemination of Incredible Years in Welfare Systems:

Implications of the Case of "Cathy" for Intervention in the Foster Care System

A. S. Gartenberg \& L. R. Lang

Pragmatic Case Studies in Psychotherapy, http://pcsp.libraries.rutgers.edu

Volume 12, Module 2, Article 3, pp. 124-138, 06-29-16 [copyright by authors]

Rogers and colleagues (2016) described efforts to ensure that shelter residents could access services. They removed barriers associated with financial limitations, transportation, childcare, and other life stresses (Webster-Stratton \& Reid, 2013). Most importantly, group leaders went into the shelter to deliver the treatment rather than requiring residents to come to the clinic. Further, they led parent and child groups concurrently and provided childcare for ineligible young children to enable parents to attend and benefit from services. Additionally, the group leaders accommodated inevitable changes related to housing status, by creating an open group format in which members could join the program when entering the shelter or leave when moving elsewhere. Although leaders could not provide the continuous, long-term care as desired, the flexibility in membership provided opportunities for members to access IY to the extent possible.

Many efforts were made to encourage participation and create a safe environment. Participation in treatment was incentivized in several ways. In addition to the convenience of inshelter treatment and childcare, participation met shelter requirements for parenting classes, members were provided with meals, and children were provided tangible rewards for goal achievement (Rogers et al., 2016). Group leaders demonstrated outstanding efforts to connect and be present with participants through weekly check-ins before or after sessions and home visits. Such consistency demonstrated genuinely compassionate care that facilitated the rapportbuilding necessary for treatment gains. Similar mistrust or uncertainty was seen in Cathy, who appeared withdrawn from initial sessions and appeared reluctant to participate actively at times. Extended playtime was provided to help her to feel more comfortable with the group environment (Rogers et al., 2016).

The IY group facilitators also employed trauma-informed strategies to overcome barriers related to parent and child engagement, as seen in "tardiness and unfocused participation" (Rogers et al., 2016, p. 60). Building on the collaborative nature of IY, group leaders incorporated recommendations for implementation of IY with families involved in child welfare services (Webster-Stratton \& Reid, 2012). They responded sensitively to parents' trauma reactions (Rogers et al., 2016). For example, facilitators recognized that many parents were triggered by the pre-treatment administration of the Detailed Assessment of Posttraumatic Stress (DAPS, Briere, 2001). As a result, they invited open discussion about the assessment and the clinicians' decision to withdraw the DAP from the post-treatment assessment battery (Rogers et al., 2016). The responsiveness and sensitivity of clinicians in such decisions and discussions reflected their trauma-informed commitment to creating a safe environment and prioritizing the best interests of the members above all else in treatment planning and evaluation. The parents reported feeling heard and validated by the leaders' management of these aspects of the treatment.

Other trauma-informed practices utilized in the case include psychoeducation on trauma and discussion of its impact on their daily lives, and coordination of referrals for affordable trauma-focused therapy for parents in need (Rogers et al., 2016). Additionally, the advanced parenting program was delivered by extending treatment to meet parents' own needs related to 
Considerations for the Dissemination of Incredible Years in Welfare Systems:

Implications of the Case of "Cathy" for Intervention in the Foster Care System

A. S. Gartenberg \& L. R. Lang

Pragmatic Case Studies in Psychotherapy, http://pcsp.libraries.rutgers.edu

Volume 12, Module 2, Article 3, pp. 124-138, 06-29-16 [copyright by authors]

emotion regulation. Fundamental parenting skills were reinforced through the use of all available video modeling clips and additional opportunities for role plays and rehearsal of skills.

These extra efforts of leaders to communicate and connect with members also provided opportunities to support parents, who despite receptiveness to treatment, struggle to practice skills learned in the group sessions. Home visits with one parent group leader and one child group leader provided opportunities for observation and discussion of progress and barriers to implementation. Leaders facilitated practice of skills and provided meaningful in-vivo feedback. They reinforced skills by incorporating IY visual aides (e.g., behavior charts, relaxation and coping skill sheets, and cue cards); and they collaborated to develop more "positive family living structure” (e.g., organization and routine) that encouraged skill usage (Rogers et al., 2016, p. 53).

Leaders collaborated consistently with parents, as well as with each other, in order to monitor the fidelity of their treatment and share information to aid in treatment planning. Home visits and parent consultation offered support as well as cohesion. Leaders of each program consulted to review the course of their group treatment. The four leaders of the parent and child programs collaborated to review progress and treatment considerations, and also sought training and supervisory consultation from an IY certified trainer (Rogers et al., 2016). This reflects trauma-informed practices of supporting all providers and parties involved in the care of traumaexposed youth (Klain \& White, 2013).

Adaptations for children involved in the child welfare system include the increased emphasis on emotions (Webster-Stratton \& Reid, 2012). For instance, extra time can be devoted to teaching emotion identification, normalizing the experience of a range of emotions, and promoting awareness of physical, cognitive, and behavior patterns associated with emotions. Facilitators might pay particular attention to positive emotions, which are less often recognized in youth involved in the child welfare system. In discussing anger, children are taught that all emotions are acceptable and normal, but adaptive management of emotions is important. They also learn that the experience of a negative emotions, like anger, is not mutually exclusive from love. Parents can be angry and still love their children, but aggressive displays of emotion (e.g, abuse) are unacceptable.

In the Case of Cathy, puppets were used to demonstrate the impact and reparation of an angry outburst. Although Cathy appeared startled during a dramatic exchange with puppets, she observed how people might apologize and repair relationships after misbehavior and how people might recover from and forgive the unsettling behaviors of others. Cathy witnessed a discussion on how to recognize inappropriate or harmful expressions of emotions, consider the impact of behavior on others, and apply more adaptive problem solving and conflict resolution strategies.

Children with trauma histories and insecure attachments might struggle with separations and reunifications. To increase Cathy's sense of safety in the group setting, her older sister was included. Group leaders also used core IY strategies that are particularly valuable for insecurely attached children, namely, the development of routines for the beginning, middle, and end of sessions. The leaders extended the playtimes to further contribute to the sense of safety and 
relationship building, but structured in-session routines helping children settle into group sessions and prepare for the end of sessions and treatment. Leaders provided opportunities for planned goodbyes, which can serve as corrective experiences for youth who have moved or changed providers abruptly and often. Rogers and colleagues (2016) described how termination was processed and how graduation enabled the families to celebrate accomplishments.

In their adaptation of the IY program, Rogers and colleagues (2016) addressed a number of content areas identified as vital for the treatment of foster care youth, who share experiences and exhibit psychological symptoms similar to those displayed by Cathy. For instance, through these trauma-informed adaptations derived from the child welfare literature, the group leaders addressed attachment and adaptive family functioning, processing of and attention to trauma, and preparation for transitions. This implementation of the IY program also meets broader recommendations for trauma-informed care, including flexible service delivery to the greatest extent possible and the promotion of collaborative, empowering, and comprehensive care.

\section{Additional IY Adaptations in the Child Welfare and Foster Care Literature}

Additional trauma-informed recommendations can enhance care for youth like Cathy, or families in other placements. Families with different living and custody arrangements might require different supports. For instance, education and collaboration amongst all providers can be advantageous to youth in the foster care system. Additional service providers, such as teachers and caseworkers, might participate in consultation or concurrent IY programs. Parents without custody of their children may have limited opportunities to practice skills learned in IY groups and foster caregivers might not receive the recommended dosage of the IY treatment. However, the training of individuals who supervise visits of birth parents and their children who are living in foster care placements and caseworkers can promote skill acquisition and generalization, thus, maximizing the growth and wellness of children and caregivers, and ideally, placement stability.

As an example, visitation supervisors trained in IY can collaborate with implementers and birth parents to focus on targeted goals. With knowledge of the program, they can more effectively guide parents in their efforts to use positive parenting practices and strengthen attachments during visits. Similarly, child welfare workers conducting home visits can use manualized IY materials to deliver interventions to caregivers. In these arrangements, different tasks might be assigned as homework (e.g., practice skills in adult relationships, reading chapters or viewing videos from IY materials). Increased collaboration and competency across providers is expected to confer the greatest benefits to caregivers and children alike.

\section{SUMMARY}

The Case of Cathy raises issues related to the common experiences of adversity and barriers to the treatment of families in transitional housing and the child welfare system. Histories of trauma and instability increase risk for a range of behavioral, social, and emotional difficulties that impact functioning across settings. Rogers and colleagues (2016) offer rich and detailed insights into the nuances of trauma-informed adaptations and treatment planning. They 
demonstrate ways to personalize treatment within the confines of a structured shelter and social services system, and translate recommendations in the literature into a meaningful and inspiring account of effective treatment for vulnerable populations in complex natural settings.

The Case of Cathy raises important issues about the common experiences of disadvantaged families within welfare systems. These challenges highlight the prevalence of psychological problems and the need for easily accessible and high quality services. Characteristics of these families and the systems within which they are served present challenges that must be overcome through the sensitive integration of trauma-informed practices. These include widespread education about trauma and evidence-based practices, special attention to creating safe environments and trusting relationships, and flexible efforts to reduce financial and other pragmatic burdens. Rogers and colleagues' (2016) account of IY in a transitional housing shelter reflect these broader issues that necessitate system-wide reform and individualized treatment, and illustrate how providers can promote wellness of youth, like Cathy, with personal and family histories of transience and trauma.

\section{REFERENCES}

Anooshian, L. J. (2005). Violence and aggression in the lives of homeless children: A review. Aggression and Violent Behavior, 10, 129-152.

Aratani, Y. (2009). Homeless children and youth: Causes and consequences. New York: National Center for Children in Poverty, Columbia University. Retrieved from http://nccp.org/publications/pdf/text_888.pdf

Austin, L. (2005). Unlocking mental health services for youth in care. Children's Voice, 14(3), 613.

Baker, A. J. K., Brown, E., Schneiderman, M., Sharma-Patel, K., \& Berrill, L. M. (2013). Application of evidence-based therapies to children in foster care: A survey of program developers. APSAC Advisor, 27(1), 27-34.

Briere, J. (2001). Detailed Assessment of Posttraumatic Stress (DAPS). Odessa, Florida: Psychological Assessment Resources.

Burns, B. J., Phillips, S. D., Wagner, H. R., Barth, R. P., Kolko, D. J., Campbell, Y., \& Landsverk, J. (2004). Mental health need and access to mental health services by youths involved with child welfare: A national survey. Journal of the American Academy of Child \& Adolescent Psychiatry, 43(8), 960-970.

Bywater, T., Hutchings, J., Linck, P., Whitaker, C., Daley, D., Yeo, S. T., \& Edwards, R. T. (2011). Incredible Years parent training support for foster carers in Wales: a multi-centre feasibility study. Child: care, health and development, 37(2), 233-243.

Chadwick Trauma-Informed Systems Project. (2013). Creating trauma-informed child welfare systems: A guide for administrators (2nd ed.). San Diego, CA: Chadwick Center for Children and Families

Children's Bureau. (2005). The AFCARS (Adoption and Foster Care Analysis and Reporting System) Report. Retrieved from http://www.acf.hhs.gov/programs/cb/publications/afcars/report9.pdf 
Cosgrove, S., Frost, C., Chown, R., \& Anam, T. (2013, May). Strengthening health outcomes for foster care children. Madison, WI: Wisconsin Department of Chkldren and Families. Retrieved from: http://www.lafollette.wisc.edu/images/publications/workshops/2013DCF-DHS.pdf

Culhane, J. F., Webb, D., Grim, S., \& Metraux, S. (2003). Prevalence of child welfare services involvement among homeless and low-income mothers: A five-year birth cohort study. Journal of Sociology \& Social Welfare, 30, 79-95.

Ehrle, J., \& Geen, R. (2002). Kin and non-kin foster care-findings from a national survey. Children and Youth Services Review, 24(1), 15-35.

Ehrle, J., Geen, R., \& Clark, R. (2001). Children cared for by relatives: Who are they and how are they faring? New Federalism: National Survey of America's Families, Series B, No. B-28. Assessing the New Federalism: An Urban Institute Program to Assess Changing Social Policies.

Grayson, J. (2012). Mental health needs of foster children and children at risk of removal. American Psychological Association Children, Youth, and Families Office Newsletter.

Horwitz, S., Owens, P., \& Simms, M. (2000). Specialized assessments for children in foster care. Journal of the American Academy of Pediatrics, 106, 59-66.

Huber, J., \& Grimm, B. (2004). Child \& family services reviews, part V: Most states fail to meet the mental health needs of foster children. Youth Law News, 25(4), 1-13.

Hutchings, J., \& Bywater, T. (2013). Delivering the Incredible Years parent programme to foster carers in Wales: Reflections from group leader supervision. Adoption \& Fostering, 37(1), 28-42.

Klain, E. J., \& White, A. R. (2013). Implementing trauma-informed practices in child welfare. ABA Center on Children and the Law: State Policy and Reform Center. Retrieved from: http://childwelfaresparc.org/wp-content/uploads/2013/11/Implementing-TraumaInformed-Practices.pdf

Kortenkamp, K., \& Ehrle, J. (2002). The well-being of children involved with the child welfare system: A national overview. New Federalism: National Survey of America's Families, Series B, No. B-43. Assessing the New Federalism: An Urban Institute Program To Assess Changing Social Policies.

Landsverk, J. A., Burns, B. J., Stambaugh, L. F. \& Rolls Reutz, J. A. (2006, February). Mental health care for children and adolescents in foster care: Review of research literature. Casey Family Programs. 9-30. Retrieved from http:// www.casey.org/Resoures/Publications/pdf/ MentalHealthCareChildren.pdf

Lee, B. A., Tyler, K. A., \& Wright, J. D. (2010). The new homelessness revisited. Annual Review of Sociology, 36, 501-521.

Linares, L. O., Montalto, D., Li, M., \& Oza, V. S. (2006). A promising parenting intervention in foster care. Journal of Consulting and Clinical psychology, 74(1), 32.

Marcynyszyn, L. A., Maher, E. J., \& Corwin, T. W. (2011). Getting with the (evidence-based) program: An evaluation of the Incredible Years Parenting Training Program in child welfare. Children and Youth Services Review, 33(5), 747-757.

Marshall, A.W. (2004, Winter). A system of care: Meeting the mental health needs of children in foster care. Mental Health in Child Welfare, 19-23. 
McDaniel, B., Braiden, H. J., Onyekwelu, J., Murphy, M., \& Regan, H. (2011). Investigating the effectiveness of the Incredible Years basic parenting programme for foster carers in Northern Ireland. Child Care in Practice, 17(1), 55-67.

McMillen, J., Scott, L.D., Zima, B.T., Ollie, M.T., Munson, R., Spitznagel, E. (2004). Use of mental health services among older youths in foster care. Psychiatric Services, 55, 811817.

Menke, E. (1998). The mental health of homeless school-age children. Journal of Child and Adolescent Psychiatric Nursing, 11, 87-98.

National Center on Family Homelessness. (1999). Homeless children: America's newest outcasts. Newton, MA: Author.

National Center on Family Homelessness. (2011). America’s youngest outcasts 2010. Newton, MA: Author. Retrieved from http://www.homelesschildrenamerica.org/media/NCFH_AmericaOutcast2010_web.pdf

National Center on Family Homelessness. (2009). America's youngest outcasts: State report card on child homelessness. Newton, MA: Author. Retrieved from: http://www.canatx.org/CAN-Research/Reports/2009/rc_full_report.pdf

National Child Traumatic Stress Network. (2008). National child traumatic stress network resources. Retrieved from: http://www.nctsn.org

Neiheiser, L. M. (2015). Students in foster care: Individualized school-based supports for successful lives. School Psychology Forum, 9(1), 21-31.

Nilsen, W. (2007). Fostering futures: A preventive intervention program for school-age children in foster care. Clinical Child Psychology and Psychiatry, 12(1), 45-63.

Obradović, J. (2010). Effortful control and adaptive functioning of homeless children: Variablefocused and person-focused analyses. Journal of Applied Developmental Psychology, 31, 109-117.

Pecora, P. R., Jensen, P. S., Romanelli, L. H., Jackson, L. J., \& Ortiz, A. (2009). Mental health services for children placed in foster care: An overview of current challenges. Child Welfare, 88(1), 5-26.

Pecora, P. J., Kessler, R. C., Williams, J., O'Brien, K., Downs, A. C., English, D., White, J., Hirpi, E., White, C. R., Wiggins, T., \& Holmes, K. E. (2005). Improving family foster care: Findings from the Northwest foster care alumni study. Seattle, WA: Casey Family Programs. Retrieved from: http://www.casey.org/media/AlumniStudies_NW_Report_FR.pdf

Pilowsky, D. (1995). Psychopathology among children placed in family foster care. Psychiatric Services, 46, 906-910.

Rogers, K.C., Bobich, M., \& Heppell, P. (2016). The impact of implementing an "Incredible Years" group within a family living unit in a transitional living shelter: The case of "Cathy." Pragmatic Case Studies in Psychotherapy, 12(2), Article 1, 65-112. Available: pcsp.libraries.rutgers.edu

Rosenkranz, B. (April 2006). Information packet: Mental health care issues for children and youth. New York: National Resource Center for Family-Centered Practice and Permanency Planning. Retrieved from http://www.hunter.cuny.edu/socwork/nrcfcpp/downloads/information_packets/ $\underline{\text { mental_health_care_issues.pdf }}$ 
Rubin, D., Alessandrini, E.A., Feudtner, C., Mandell, D. S., Localio, A. L., \& Hadley, T. (2004). Placement stability and mental health costs for children in fostercare. Journal of the American Academy of Pediatrics, 113, 1336-1341.

Stahmer, A. C., Leslie, L. K., Hurlburt, M., Barth, R. P., Webb, M. B., Landsverk, J., \& Zhang, J. (2005). Developmental and behavioral needs and service use for young children in child welfare. Pediatrics, 116(4), 891-900.

Webster-Stratton, C., \& Reid, M. J. (2003). Treating conduct problems and strengthening social and emotional competence in young children: The Dina Dinosaur Treatment Program. Journal of Emotional and Behavioral disorders, 11(3), 130-143.

Webster-Stratton, C., \& Reid, M. (2010). Adapting the Incredible Years, an evidence-based parenting program for families involved in the child welfare system. Journal of Children's Services, 5(1), 25-42.

Webster-Stratton, C., \& Reid, M. J. (2012). The Incredible Years: Evidence-based parenting programs for families involved in the child welfare system. In A. Rubin (Ed.), Programs and interventions for maltreated children and families at risk, 11-30. New Jersey: John Wiley \& Sons. Also available online: http://incredibleyears.com/article/the-incredible-years-evidence-based-parenting-andchild-programs-for-families-involved-in-the-child-welfare-system/

Zima, B., Bussing, R., Crecelius, G., Kaufman, A., \& Belin, T. (1999). Psychotropic medication use among children in foster care: Relationship to severe psychiatric disorders. American Journal of Public Health, 89, 1732-1735.

Zlotnick, C. (2009). What research tells us about the intersecting streams of homelessness and foster care. American Journal of Orthopsychiatry, 79(3), 319.

Zlotnick, C., Kronstadt, D., \& Klee, L. (1998). Foster care children and family homelessness. American Journal of Public Health, 88(9), 1368-1370. 